\title{
Labor protection laws and the drain on productivity: Evidence from India
}

\author{
By
}

Daniel Schwab

August 2019

\section{COLLEGE OF THE HOLY CROSS, DEPARTMENT OF ECONOMICS FACULTY RESEARCH SERIES, PAPER NO. 19-06*}

\author{
Department of Economics \\ College of the Holy Cross \\ Box 45A \\ Worcester, Massachusetts 01610 \\ (508) 793-3362 (phone) \\ (508) 793-3708 (fax)
}

https://www.holycross.edu/academics/programs/economics-and-accounting

*All papers in the Holy Cross Working Paper Series should be considered draft versions subject to future revision. Comments and suggestions are welcome. 


\title{
Labor protection laws and the drain on productivity: Evidence from India
}

\author{
By \\ Daniel Schwab ${ }^{\dagger}$ \\ College of the Holy Cross
}

August 2019

\begin{abstract}
Employment protection legislation (EPL) is designed to promote security for workers by placing restrictions on firing, but it generates unintended consequences. With India as a setting, I argue that EPL shifts jobs from younger to older workers in two ways: by discouraging the hiring of unproven young workers and by preventing the firing of low-productivity workers. The identification strategy is motivated by Rajan and Zingales (1998): I assume that EPL is more binding in those manufacturing sectors where the involuntary separation rate in other countries is high. The data show that older workers are more likely to have formal jobs, and the effect is strongest in high-firing sectors, which indicates EPL shifts jobs from young to old. Additionally, EPL reduces plant-level total productivity (TFP), and this effect is seen only in plants which are large enough to fall within the purview of EPL, which provides a useful placebo test.
\end{abstract}

Keywords: Unemployment, labor security

JEL Codes: J83, J60

${ }^{\dagger}$ Department of Economics and Accounting, College of the Holy Cross, 1 College Street Worcester, MA 01610, 508-793-3526 (phone), 508-793-3708 (fax), dschwab@holycross.edu 


\section{Introduction}

This paper explores unintended consequences of employment protection legislation (EPL), which limits the ability of employers to fire workers. Nearly every country in the world has some form of EPL, which can be a requirement of advance notice, a severance payment, a prohibition on firing, or some combination of these (World Bank 2015). One common argument in favor of these laws is that they reduce income risk in the absence of perfectly functioning insurance markets (Pissarides 2001). Although there may be benefits, EPL carries the risk of creating distortions by preventing a firm from firing a low-productivity worker.

The setting is India's manufacturing sector, which has some of the strictest EPL in the world (World Bank 2008), so the distortions it creates are large and important for the Indian economy. In addition, there is considerable variation in state-level EPL, meaning that it is possible to restrict attention to a single country, ensuring that much of the institutional environment is the same across the data.

India's main labor law is the Industrial Disputes Act (IDA), which requires large plants to obtain government permission before the plants can fire a permanent worker. Contract workers, who are employed through contractors and not directly employed by the firm where they work, are not protected and can be fired freely in all plants. Additionally, EPL does not apply to plants below a size threshold. Finally, employees who are above the retirement age of 58 are also not protected, and are not included in the sample. Permanent workers in large plants are protected by EPL, and I call them "formal"; informal workers are either contract workers or in a small plant.

EPL leads to an older formal workforce by distorting the hiring decision and by preventing firing. A forward-looking firm is reluctant to hire a young worker if it will not be able to fire her if she turns out to be unproductive. Older workers are especially "safe" in India, because is no risk of an unproductive worker staying on past retirement age. Now suppose that an employee's performance is poor. In the absence of EPL, the firm can fire the worker and hire someone else. New hires tend to be young, so this dismissal makes the labor force younger. On the other hand, if a firm is disallowed from firing because of EPL, then the worker will remain with the firm, so the labor force will be older.

First I demonstrate a correlation: in states with stricter EPL, older workers are more likely to be formal. The strength of a state's EPL is calculated by aggregating the ratings of three earlier papers. To argue that stronger EPL causes older workers to be in the formal sector, as opposed to the results being driven by an omitted variable or reverse causality, I consider heterogeneity across manufacturing sectors. The broad strategy is to argue that some manufacturing sectors are more impacted by EPL than others, which is motivated by Rajan and Zingales (1998). If EPL causes the formal sector to be older, then older workers should be especially likely to be in the formal sector if they work in strict-EPL states 
and in sectors where EPL often binds.

It is not possible to observe directly which sectors would have the most firing in the absence of EPL, but United States involuntary separation rates are instructive because the US has very weak EPL. ${ }^{1}$ There is a strong correlation between the rank of involuntary separation rates from one country to another (Micco and Pagés 2006), which provides some reassurance that the rank of separation rates is driven by technology or other characteristics of the sector rather than by idiosyncratic country-specific factors. ${ }^{2}$ That is, EPL causes the shift in jobs from young to old because older workers are especially likely to be formal in strict-EPL states in manufacturing sectors where the involuntary separation rate in the United States is high.

A similar empirical strategy can be used to address whether EPL has a measurable effect on plantlevel total factor productivity (TFP) of large plants. I test whether TFP is lower when the state has a high value for the interaction between strict state-level EPL and the high sector-level involuntary separation rate. Among plants large enough to be affected by EPL, there is a negative relationship between TFP and this interaction term. Smaller plants provide a useful placebo test, and there is no relationship between TFP and this interaction for plants that are too small to be affected by EPL, which suggests that EPL does in fact reduce TFP.

A plausible explanation is that the EPL reduces TFP because it distorts the age profile of workers, but I do not address the mechanism in the present paper. For example, it is also possible that the effect on TFP of the distortion of the age profile is quite small, and the entire reduction in TFP operates through the channel of distorting the size of firms (Amirapu and Gechter 2018) or deterring potential entrepreneurs.

This paper connects two branches of the labor literature. The first is a body of literature that shows that EPL has negative effects on the employment prospects of the young. Notable papers in this vein include: Montenegro and Pagés (2004) in Chile, Heckman and Pagés (2000) in Latin America, Skedinger (1995) in Sweden, and Esping-Andersen (2002) and OECD (2004) in Europe. This literature has been concentrated in wealthy or middle-income countries, and the present paper is the first to find this effect in India.

The second strand of literature contends that EPL reduces productivity. The canonical paper in this thread is Besley and Burgess (2004), which focused on India, and there have been many other papers which found similar results across a wide variety of countries. See, for example, Bassanini et al. (2009) in OECD, Okudaira et al. (2013) in Japan, Autor et al. (2007) in the United States, and Dougherty et al.

\footnotetext{
${ }^{1}$ Using the firing rate in India would be problematic because it would be difficult to distinguish between strict enforcement of EPL in a sector and a naturally low firing rate.

${ }^{2}$ Bassanini et al. (2009) also use the involuntary separation rate of the United States as a proxy for the firing rate of a manufacturing sector that would prevail in the absence of EPL.
} 
(2014) in India. The present paper is firmly in agreement with earlier research, and also argues that EPL reduces TFP.

The rest of the paper is organized as follows. Section 2 provides background information on the relevant legal institutions of India. Section 3 presents a theoretical model. Section 4 outlines the data, the empirical strategy, and the results, and Section 5 concludes.

\section{Formality and EPL in India}

In order to be protected under Chapter VB of the Industrial Disputes Act, a worker must meet several qualifications, but if a worker is protected, then it is very difficult for her employer to fire her (Ahsan and Pagés 2007). First, she must be a regular employee, as opposed to a contract worker; contract workers are hired through outside firms rather than being hired directly. Contract workers have become more common during the past several decades, and may be fired by firms without government permission (Chaurey 2015). Employers cannot dodge EPL by relying entirely on contract workers, because if the principal employer exercises direct control over workers employed through an outside firm, those workers become regular workers and are entitled to the protections of the IDA (Kumar 2008).

Second, workers are only protected if they are in a plant that is sufficiently large. The employment threshold where Chapter VB applies varies by state; Uttar Pradesh has set the threshold to 300, and West Bengal's threshold is 50, and all others are 100. No state changed this threshold or made any other meaningful changes to the IDA during the span of the data used in this paper, so the analysis relies on the interaction of time-invariant strictness of EPL and sector heterogeneity, rather than on intertemporal variation.

Most of the differences between states' EPL affects other issues. For example, Andhra Pradesh passed an amendment to the IDA in 1987 that extends the notice that must be given to a worker before the terms of her job can be changed, which is a strengthening of the IDA; see Malik (2011) for more details.

Finally, EPL no longer applies once a worker has reached retirement age. If that age is not specified in the contract of a manufacturing worker, the default is 58 years old, and in practice that is almost always the age that applies.

\section{Theory}

This section will develop a model that illustrates how EPL impacts a firm's decision between an old and a young employee, and the implications for productivity. That main tradeoff is that a firm is willing to hire a less productive older worker in order to preserve flexibility for the next period. 
A firm chooses between a young and old employee in every period, but if it hires a young employee, it may be constrained by EPL to retain that employee in the following period. In some manufacturing sectors, the old have comparative advantage relative to the young. For example, old workers may be more productive than young workers in tasks requiring human capital that is built up over a career, while young workers are more effective at physical labor. EPL is less important in manufacturing sectors where older workers are more productive, because firms can hire an old worker, employ her until retirement, and then hire another old worker. ${ }^{3}$

I abstract from a number of important issues, such as how a firm chooses its number of employees (and therefore whether or not it crosses the employment threshold to be affected by EPL), ${ }^{4}$ how wages are affected by EPL, and the role of competition. In practice, large firms employ a mix of regular workers and contract workers, but a given worker is likely to be more productive as a regular worker than a contract worker, because of the restrictions on the tasks that a contract worker can perform and on the control that managers can exert on a contract worker. In the interest of simplicity, I abstract from the issue of contract workers at large firms for the purpose of the theory.

\subsection{Firms}

When a firm is created, I assume that its level of labor $L$ is exogenously given and fixed over time, and $L \geq 100$. Each of the $L$ positions operates independently of the other, with no economies of scale. The $l$-th worker in the firm in period $t$ has productivity $\theta_{l t}$, and the firm's only cost is wages, so the firm's present discounted profit is

$$
\operatorname{Profit}_{m}=\sum_{t=0}^{\infty} \beta^{t} \sum_{l=1}^{L}\left(\theta_{l t}-w_{l t}\right)
$$

where $\beta$ is the discount rate. Firms and workers both take their manufacturing sector and state as fixed. The wage-setting process will be described below.

\subsection{Labor market and timing}

A risk-neutral firm is created in period 0 and is matched with one young and one old worker for each of its $L$ positions. I assume that a worker applies for a specific position at a firm, meaning that if a firm will have $L$ employees, it chooses between one young and one old applicant for each position.

\footnotetext{
${ }^{3}$ Alternatively, the model could be designed so that sector heterogeneity is based on returns to experience within a particular firm, or so the preciseness of the signal of the young worker's ability varies across sectors.

${ }^{4}$ For example, Hasan and Jandoc (2010) show that EPL reduces firm size.
} 
The employee works and receives a wage, and the firm realizes a profit that is the difference between the wage and the worker's productivity. In the following period the old worker retires, the young worker becomes old, and a new young worker arrives.

If the firm hired the old worker in period 0 , then she retires after period 0 , and in period 1 the firm is uncommitted and may hire either the old worker or the new young worker. If the firm hired the young worker in period 0, then it learns in period 1 whether EPL is enforced; EPL is enforced with probability $e$, where high $e$ corresponds to strict EPL. If EPL is not enforced then the firm is again uncommitted in period 1 and may employ the young or old worker.

If EPL is enforced then the worker who was employed in period 0 (while young) is protected and must also be employed in period 1 (while old). ${ }^{5}$ The protected worker retires at the end of period 1 and the firm is free in period 2 to hire the young or old worker, and is in the identical position as it was in period 0 . This process continues for an infinite number of periods.

\subsection{Productivity and information}

A young worker has productivity $\theta \sim U[\underline{\theta}, \underline{\theta}+1]$, but the realization is not observed by the firm. The firm knows the distributions of all of the variables, and knows that each draw of $\theta$ is independent. An old worker has productivity $\theta \sim U[\underline{\theta}-f, \underline{\theta}+1-f]$, where $-1 / 2<f<1 / 2$ is specific to the manufacturing sector and exogenous for the firm. The bounds on $\underline{\theta}$ and $f$ are chosen to ensure an interior solution, and to guarantee positive productivities. A high value of $f$ means that young workers in the sector are relatively productive, so firing is frequent.

I assume the firm observes the old worker's productivity perfectly, because the old employee has a verifiable track record. ${ }^{6}$

\subsection{Wages}

There are many more workers in India who want formal sector jobs than there are available positions (Rajeev 2010), so I assume that a worker who passes up an opportunity at a formal job ends up in the informal sector. A worker with productivity $\theta$ in the formal sector has productivity of $\alpha \theta$ in the informal sector, where $0 \leq \alpha<1$ is constant across workers, manufacturing sectors, and states. The informal sector is competitive, with no search frictions, so a worker earns here expected productivity. A young worker's expected productivity in the formal sector is $\underline{\theta}+1 / 2$, so her outside option is to work

\footnotetext{
${ }^{5}$ In practice, EPL sometimes makes firing costly, either in terms of time or money, rather than making firing literally impossible. In addition, firms have some ability to worsen conditions to encourage an unproductive employee to quit, but courts have imposed limitations on such behavior.

${ }^{6}$ This assumption could easily be relaxed, since the firm is risk-neutral and the old worker will retire after the next period.
} 
in the informal sector for a wage of $\alpha(\underline{\theta}+1 / 2)$. Firms can observe an old worker's productivity in the formal sector, $\theta$, so firms also know that her productivity in the informal sector is $\alpha \theta$.

When a firm retains an employee, whether because it chooses to or because it has been forced to by EPL, the firm makes a new wage offer. This new wage takes into account the worker's productivity, which has now been revealed. EPL does place restrictions on pay reductions, but employers often do have some leeway in renegotiating wages (or simply not offering raises), so I assume that EPL prevents firing, but does not impact wage setting.

When the formal sector firm has chosen which worker to hire, it makes a take-it-or-leave-it offer to the worker equal to the worker's outside option. If it chooses the young worker, it offers a wage of $\alpha(\underline{\theta}+1 / 2)$, and if it chooses the old worker, it offers $\alpha \theta$. Hiring the young worker gives the firm an expected profit of $(1-\alpha)(\underline{\theta}+1 / 2)$, while hiring the old worker gives the firm a profit of $(1-\alpha) \theta$.

\subsection{A firm's decision}

Each position is independent of the others, so the firm's problem is to maximize the profits from a single position within the firm. The discounted profit for position $l$ is,

$$
\text { Profit }_{l}=(1-\alpha) \sum_{t=0}^{\infty} \beta^{t} \theta_{l t}
$$

Every period in which the firm has a choice between the workers is identical, so without loss of generality the firm chooses a threshold $z-f+\underline{\theta}$, where it hires an old worker if the old worker has productivity of at least $z-f+\underline{\theta}$. In periods when it has the choice of employees, the firm chooses the young worker with probability $z$.

The firm's present discounted profit (starting when the firm is not committed to a worker) is $V(z)$. If the firm hires the young worker in period 0 , her expected productivity is $\underline{\theta}+1 / 2$ in period 0 . With probability $e$, it must retain the employee, meaning the expected productivity is $(\underline{\theta}+1 / 2-f)$ in period 1 , and then the worker retires and the firm is uncommitted in period 2, so it receives $V(z)$ as a continuation value, starting in period 2. If it is allowed to fire her in period 1, then it has continuation value of $V(z)$ starting in period 1. Therefore, the discounted sum of expected productivities when hiring the young worker is $\left(\underline{\theta}+1 / 2+e\left[\beta(\underline{\theta}+1 / 2-f)+\beta^{2} V(z)\right]+(1-e) \beta V(z)\right)$.

If the firm hires the old worker, her productivity is distributed $U[z-f+\underline{\theta}, 1-f+\underline{\theta}]$, so her expected productivity is $\underline{\theta}+((z-f)+(1-f)) / 2=\underline{\theta}+(z+1) / 2-f$. The firm then earns continuation value of $V(z)$ starting in period 1 . The firm is free to hire either worker in period 0 , so the probability of hiring 
the young worker in period 0 is $z$.

The firm's profit as a function of $z$ is

$$
\begin{aligned}
V(z)= & z\left(\underline{\theta}+1 / 2+e\left[\beta(\underline{\theta}+1 / 2-f)+\beta^{2} V(z)\right]+(1-e) \beta V(z)\right)+ \\
& (1-z)[(z+1) / 2-f+\underline{\theta}+\beta V(z)]
\end{aligned}
$$

Solving for $V(z)$

$$
V(z)=\left(-1+2 f-z-2 f z+z^{2}-e z \beta+2 e f z \beta\right) /(2(-1+\beta)(1+e z \beta))+\underline{\theta} /(1+\beta),
$$

and maximizing over $z$ yields the optimal choice of $z$ :

$$
z^{*}= \begin{cases}\frac{\sqrt{\beta e+2 \beta e f+1}-1}{\beta e} & e>0 \\ 1 / 2+f & e=0\end{cases}
$$

Note that it can be verified that this expression is smooth at $e=0$. To gain some intuition behind this expression, consider the special case where $e=f=0$. Old and young workers are equally productive, and the firm is free to fire any worker, so the firm will choose whichever worker has the higher productivity in every period, so the probability of hiring the young worker, $z^{*}$, is equal to $1 / 2$. Equation (5) confirms that $z^{*}=1 / 2+f=1 / 2$.

It is also possible to confirm that $z^{*}$ is decreasing in $e$, meaning that uncommitted firms are more reluctant to hire the young when EPL is more strictly enforced.

\subsection{Individual-level outcomes}

The first question is how the likelihood of a young person being employed depends on the strictness of EPL. A change in EPL impacts how often a firm is uncommitted and how often it hires a young worker when it has the option to do so. If a firm is committed with probability $c_{t}$ in period $t$, then in order for it to be committed in period $t+1$, it must be uncommitted in period $t$, choose the young worker in period $t$, and be unable to escape its commitment. In symbols, $c_{t+1}=\left(1-c_{t}\right) e z^{*}$. The value of $c$ varies over the life of a firm, because a new firm is uncommitted by assumption, and approaches a steady state over time. In the steady state, a firm is committed with probability $e z^{*} /\left(1+e z^{*}\right)$. It hires a young worker when uncommitted with probability $z^{*}$, so in the steady state, the firm employs a young 
worker with probability $z^{*} /\left(1+e z^{*}\right)$.

Thus, the impact of an increase on the employment of the young is equal to $\frac{\partial}{\partial e} \frac{z^{*}}{1+e z^{*}}$. Note that $z^{*}$ is itself a function of $e$.

Claim 1: For all $(e, f, \beta) \in(0,1) \times(-1 / 2,1 / 2) \times(0,1)$,

$$
\frac{\partial}{\partial e} \frac{z^{*}}{1+e z^{*}}<0
$$

See Online Appendix A for proof.

Prediction 1: Fewer young workers work in the formal sector in states with strict EPL.

Next, I examine whether EPL has a stronger impact in those sectors where firms would like to fire more often. First, I verify that in a zero-EPL environment, the firing rate is increasing in $f$. If $e=0$, then a firm chooses the young worker when the old worker's productivity is below $\underline{\theta}+1 / 2$, which happens with probability $1 / 2+f$. A worker is fired when the young worker is hired in two consecutive periods, so a worker is fired with probability $(1 / 2+f)^{2}$, which is increasing in $f$, the relative productivity of younger workers, if there is no EPL.

To test whether EPL has a stronger effect in sectors where firing is more attractive, I look at how the likelihood of hiring a young worker changes with a change in $e$ and $f: \frac{\partial}{\partial e \partial f} \frac{z^{*}}{1+e z^{*}}$.

Claim 2: For all $(e, f, \beta) \in(0,1) \times(-1 / 2,1 / 2) \times(0,1)$,

$$
\frac{\partial}{\partial e \partial f} \frac{z^{*}}{1+e z^{*}}<0
$$

See Online Appendix A for proof.

Prediction 2: EPL depresses a young worker's chance of being in the formal sector more strongly in manufacturing sectors where firms would like to fire workers.

\subsection{Firm-level outcomes}

A firm's profitability is a function of parameters $e, f$, and $\beta$ and the choice variable $z$. Define $\phi(e, f, \beta)$ as the profits associated with the optimal choice of $z$. We can verify that firm profitability is decreasing in EPL (claim 3):

Claim 3: For all $(e, f, b) \in(0,1) \times(-1 / 2,1 / 2) \times(0,1)$, 


$$
\frac{\partial}{\partial e} \phi(e, f, \beta)<0
$$

See Online Appendix A for proof.

Prediction 3: EPL reduces a firm's productivity.

\section{Empirics}

The model generates three predictions to be tested. Below, I explain the data sources used, the strategy used to test the predictions, and the results. Finally, I address alternate explanations for the results.

\subsection{Data}

I use data covering the following topics: individual-level employment outcomes, the stringency of EPL in each state, sector-level firing rates, and plant-level data to calculate total factor productivity (TFP).

\subsubsection{Individual-level employment outcomes}

The National Sample Survey is a nationally representative survey carried out by the central government of India. I use data from 2009-2010 and 2011-2012, the only years to include the size of the respondent's workplace, and apply the sampling weights provided. Workers are not matched between rounds of the survey, so it is not possible to track workers who move across states or drop out of the labor force. The 2009-2010 round uses the 2004 version of India's National Industrial Classification (NIC-2004), while the latter round uses NIC-2008. Details on the concordance are available upon request.

To address age heaping, I treat all workers between 38 and 42 years old as 40, all workers between 43 and 47 as 45, and so on. Workers whose contracts do not specify otherwise may be fired after age 58, and I exclude those above 57 and below 18 because laws impact those groups differently.

The definition of "formal" used in the literature varies somewhat depending on the author and the context. The central feature of formality for the present paper is protection under EPL, which applies to regular workers who are hired directly by the firm, and in a plant with at least 100 workers (this threshold is 50 in West Bengal and 300 in Uttar Pradesh). The NSS asks about the size of the establishment 
where a worker is employed, but the highest category provided is 20 or more workers, so there is some imprecision in the measure of whether a worker is protected by EPL. However, of those workers who are in a plant of at least 20 employees, $77 \%$ are in fact in a plant of at least 100 (author's calculations based on Annual Survey of Industries). I define a worker as formal if she is a regular worker in a plant with at least 20 workers.

\subsubsection{State-level EPL}

In order to classify the strictness of EPL in each of 15 major states, I follow the approach of Gupta et al. (2009; GHK), who analyze three earlier studies that classify states. The first paper in the group is Besley and Burgess (2004), which classifies states according to the text of state-level amendments to the IDA.

The second paper is by Bhattacharjea (2008), who argues that Besley and Burgess code some amendments incorrectly. Bhattacharjea presents his own classification of each amendment to the IDA, and also includes judicial rulings that impact how the IDA is applied.

OECD (2007) uses a survey to identify a range of state-level labor reforms. This study encompasses the IDA, as well as the Factories Act and the Contract labor Act, and the authors consider both the statutory laws and the enforcement mechanisms that are in place.

GHK convert each study's rating of each state into a simple strict, neutral, or lax EPL $(1,0,-1)$, so that there are three ratings for each state. I add these ratings to arrive at an overall ranking between -3 and 3, which is treated as an interval scale, and divide by 1,000 for readability.

Prediction 1 says that older workers are relatively more likely to have formal jobs in states with strict EPL. I present evidence of this correlation in Figure 1, where I split states into above- and below-median strictness of EPL and plot the fraction of workers with formal jobs across four age buckets. The data show that about 22 percent of the youngest workers in each group is formal. In states with strict EPL, the oldest group is 30 percent formal, while in the lax EPL group the formality rate is under 17 percent. This exercise is purely descriptive, and there are no fixed effects and no attempt made to adjust for controls.

To see the EPL rating of each state, please see Online Appendix Table B1.

\subsubsection{Firing rate}

My identification strategy depends on an assumption about which manufacturing sectors in India would have a high rate of firing in the absence of EPL. The first proxy that I consider is involuntary job loss rate (which is somewhat broader than firing) in the United States, which I calculate based on the 
United States CPS Displaced Worker Survey (DWS) from 2004, 2006, 2008, and 2010, following the method of Bassanini et al. (2009).

The DWS provides data on 16 2-digit manufacturing sectors. There are 20 2-digit manufacturing sectors in the NSS, classified according to the NIC-2004, and I match manufacturing sectors. Where a DWS sector encompasses two NSS sectors, I apply the DWS involuntary separation rate to both NSS sectors. Please see Online Appendix Table B2 for more details.

Using US separation rates as a proxy for which manufacturing sectors are most affected by EPL is an established strategy in the literature, but one natural concern is whether conditions in the United States are informative about India because of income differences. Latin America is still considerably wealthier than India, but it may provide some reassurance if results are similar using data from Latin American countries rather than the US. Following Davis and Haltiwanger (1999), Micco and Pagés (2006) define job reallocation as the sum of job creation and job destruction. They calculate job reallocation for eight manufacturing sectors for 18 countries, across the Americas and Europe. This measure is closely related to firing because industries with frequent firing will also have high rates of job destruction.

In order to construct a Latin American measure of firing for each of eight sectors, I take the average job reallocation rate for the seven Latin American countries with complete data: Argentina, Brazil, Chile, Colombia, Mexico, Uruguay, and Venezuela. Micco and Pagés (2006) also present the correlation in ranks of the job reallocation rate to assess the similarity between different countries (the seven Latin American countries and a number of others), and find that the correlation is quite high.

\subsubsection{Plant-level data}

The main data source to calculate TFP is the Annual Survey of Industries (ASI), from 1998-1999 to 2007-08. The ASI's sampling sector includes all plants that employ at least 20 workers without power, and at least 10 workers with power, and these plants are surveyed every several years. The census sector consists of the larger plants, but the threshold has varied between 50 and 200 over the course of the sample, meaning that plants with at least 200 have been surveyed every year. For more information regarding data issues within the ASI and the sampling procedure, see Bollard et al. (2013) and Harrison et al. (2013).

I use the Levinsohn-Petrin (2003) method to calculate (natural log of) TFP, which requires requires data on output, labor, capital, fuel, and electricity. After dropping all plant-year observations with missing or negative values, there are 126,785 observations and 54,080 unique plants. The ASI provides sampling weights for all plants, which again I use throughout.

The ASI lists values in current rupees, so I apply industry-specific deflators following the same 
method as Dougherty et al. (2014).

\subsection{Empirical strategy}

The first two predictions are tested using using individual-level outcomes from the NSS to argue that EPL shifts jobs from young to old workers. To test the third prediction that EPL reduces TFP, I examine the relationship between plant-level TFP and the interaction of EPL and firing rate in a sector-state.

\subsubsection{Testing Prediction 1: older formal sector workers in strict-EPL states}

The first question is whether older workers are relatively more likely to be in the formal sector in states with stricter EPL (Prediction 1). To test this relationship, leaving aside for now the question of causality, I consider a linear regression:

$$
\text { Formal }_{i j k t}=\beta_{1} a g e_{i j k t}+\beta_{2} a g e_{i j k t} * E P L_{k}+\delta_{j k}+\delta_{j t}+\delta_{k t}+\xi_{i}+\varepsilon_{i j k t},
$$

where $i$ indexes individuals, $j$ indexes manufacturing sectors, $k$ indexes states, and $t$ indexes years. There are dummy variables $\delta_{j k}, \delta_{j t}$, and $\delta_{k t}$ for sector-state, sector-year, and state-year fixed effects, and $\xi_{i}$ includes dummy variables for every level of education, for gender, and urban or rural residence. The dependent variable is equal to 1 if the worker is a formal employee. I conclude that the evidence is consistent with Prediction 1 if $\beta_{2}$, the coefficient on the interaction term, is positive.

Note that I estimate how EPL shifts jobs from young to old (or vice versa), but I do not estimate whether EPL creates or destroys formal sector jobs. The reason for this is that there is no time variation in EPL in time period of my data, and there are many state-level variables other than EPL that could impact the level of formality. The regression includes the interaction term $\beta_{2} a g e_{i j k t} * E P L_{k}$ but does not explicitly include $E P L_{k}$ because it is absorbed by the fixed effects.

I estimate the linear regression in (9) and the probit analogue, and results are similar in all cases. Standard errors are clustered at the state level to address the possibility of correlated errors within a state and because the variation in EPL occurs at the state level (Bertrand et al. 2004). In an additional unreported robustness check, I use the Donald and Lang (2007) estimator, which indicates that there is not a problem of too few clusters. Two-way clustering with state and sector gives similar results as well.

Table 1 presents the results from the regression of equation (9) in column 1 and the probit analogue in column 2. The coefficient on the variable of interest, the interaction between EPL and age, is positive and significant at the five percent level in both models, and this result is consistent with Prediction 1, which states that more old workers in the formal sector in states with strict EPL. 
To give a sense of the magnitude of of an interaction effect (based on column 1 of Table 1), consider a 20-year old and an otherwise-identical 55-year old worker in a weak-EPL state and in a strict-EPL state. In the state with the weakest EPL, I predict that the 20-year old worker has a 7.1 percentage point higher probability of formality than the 55-year old, while in a state with the strictest EPL, the 55-year old has a 8.8 percentage point higher chance of formality. Approximately 21 percent of both 20 -year olds and 55-year olds are formal across the entire sample, meaning the difference is substantial.

\subsubsection{Testing Prediction 2: Prediction 1 holds more strongly in high-separation sectors}

Laws are not created randomly, and while no major changes to EPL have been passed since the 1980s, it is possible that some states strengthened or weakened EPL in response to persistent conditions of the state. This endogeneity problem can be at least partially addressed by considering sector heterogeneity, where some manufacturing sectors are more impacted by EPL than others. I rely on the approach of Rajan and Zingales (1998), who test whether financial development causes economic growth by showing that countries with strong financial systems have especially strong manufacturing sectors in exactly the sectors that rely heavily on external finance (measured as those sectors where American firms use more external finance).

The argument here is similar: if EPL causes the shift in formal jobs from young to old workers, we should see that differences in EPL generate larger formality boosts to old workers in manufacturing sectors in which Indian employers would like to fire workers. The United States has some of the weakest EPL in the world, so it serves as a useful benchmark for what would happen in the absence of EPL. I use measures of job losses in the United States and Latin America as proxies for the firing rate in India.

I test Prediction 2 with the following regression:

$$
\begin{aligned}
\text { Formal }_{i j k t}= & \beta_{1} \text { age }_{i j k t}+\delta_{j k}+\delta_{j t}+\delta_{k t}+\xi_{i} \\
& \beta_{2} * \text { age }_{i j k t} * \text { fire }_{j}+ \\
& \beta_{3} * \text { age }_{i j k t} * E P L_{k}+ \\
& \beta_{4} * \text { age }_{i j k t} * E P L_{k} * \text { fire }_{j}+\varepsilon_{i j k t},
\end{aligned}
$$

and conclude there is evidence that EPL causes the different age composition if $\beta_{4}>0 .^{7}$ That is, an older worker in a high-firing sector in a strict-EPL state is more likely to have a job in the formal sector than an older worker in a high-firing sector in a lax-EPL state, because an older worker in a high-firing

\footnotetext{
${ }^{7}$ Note that $E P L_{k}$, fire ${ }_{j}$, and their interaction are not included because they absorbed by sector-state fixed effects.
} 
sectors is exactly the type of employee who is most helped by EPL.

I present results of these tests in Table 2. In columns 1 and 2, I use the US separation rate as a proxy for what the Indian separation rate would be in the absence of EPL, with linear and probit models, and results for both are positive and significant. With the Latin American firing rate (columns 3 and 4), about 10 percent of the observations are missing because of a lack of firing rate data in some manufacturing sectors. Again, in both models the coefficient of interest is positive and significant, indicating a causal relationship: EPL shifts jobs from young workers to older workers.

\subsubsection{Testing Prediction 3: EPL reduces productivity}

In this section I provide evidence EPL also reduces productivity at the plant level.

The NSS and ASI datasets are not matched, meaning it is not possible to observe the place of employment of a respondent to the NSS or the age profile of a plant in the ASI, so I use the same strategy as above and assume that sectors with high firing rates are especially affected by EPL and focus on the interaction of firing rate and EPL. The direct effects of EPL and firing rate will be captured by state and sector fixed effects, which are important because of the large number of variables that are constant across the state or sector that may influence TFP.

The lack of matching between individual-level and firm-level data precludes some empirical strategies, but there are also advantages to using sector-state level data as the independent variable in regressions with plant-level outcomes as the dependent variable. Regressing TFP of a firm on the age distribution of the workers in the same firm, for example, opens the door to endogeneity concerns if some unobserved characteristic of high productivity firms causes them to hire young (or old) workers. Focusing on variation at the sector-state level removes the possibility of plant-level endogeneity driving the results.

First, I test whether plants in sector-states in strict-EPL states and high-firing sectors have a lower TFP, which is Prediction 3. Plants with fewer than 100 workers provide a placebo test, since the main employment laws do not apply to them. I use state-year and sector-year fixed effects, and cluster at the state level (results are similar when clustering at the state and sector level). Breaking the sample into plants with more and fewer than 100 workers (and excluding West Bengal and Uttar Pradesh because they have a different threshold for the IDA), I test Prediction 3 using this regression:

$$
\ln \left(T F P_{i j k t}\right)=\beta_{1} * E P L_{k} * \text { fire }_{j}+\beta_{2} * L_{i j k t}+\delta_{j k}+\delta_{k t}+\delta_{j t}+\varepsilon_{i j k t},
$$

I conclude that EPL harms TFP if $\beta_{1}<0$ for plants with more than 100 workers and is near zero for 
plants with fewer. ${ }^{8}$

I control for the log of a plant's labor $L_{i j k t}$ to address the possibility of economies of scale, and present results above and below 100 workers, using US (columns 1 and 2) and Latin American (columns 3 and 4) separation rates.

There is a negative and significant coefficient on the interaction of EPL and separation rates for the plants with at least 100 workers (columns 1 and 3 of Table 3). The magnitude of the coefficients in plants with fewer than 100 workers (columns 2 and 4 of Table 3) is much smaller and not significant. An F-test rejects at the 1 percent level the hypothesis that the coefficients are equal using US separation rates (column 1 compared to column 2) and rejects equality at the 10 percent level using Latin American rates (column 3 compared to column 4) respectively.

These results indicate that EPL reduces plant-level TFP. The fact that there is no appreciable relationship for small plants provides some assurance that there is not some other variable that is constant within each sector-state that is driving the results.

This interaction term can be thought of as a second derivative, and to understand the magnitude, consider the following (this discussion of magnitudes follows closely from Rajan and Zingales 1998). Maharashtra has the strictest EPL, coded as 3, while Karnataka is tied for the laxest EPL at -2. Food manufacturing has the lowest firing rate (coded as 1) while manufacturing of medical instruments, watches and clocks has the highest firing rate out of the 20 sectors (coded as 20). The coefficient of -4.210 in column 1 of Table 3 implies that TFP is predicted to be lower in instrument manufacturing than food manufacturing by .400 in Maharashtra compared to Karnataka (the calculation is: $(20-1)$ * $(3+2) * 4.210 / 1000=.400)$. The standard deviation of TFP across all sectors is 1.77 , meaning that the effect of the interaction term on TFP is economically meaningful.

\subsection{Alternative explanations}

In this section I discuss some alternate explanations that could also generate the results presented above, and in some cases I present empirical analysis to test their importance.

\subsubsection{Individual-level results: Predictions 1 and 2}

Could these results be spuriously generated if the characteristics of a state influence the types of legislation they pass? For example, perhaps states passed stricter EPL if they produced heavily in "sunset industries" like textiles, industries that were in decline nationwide.

I define a sector's growth over time as the percentage growth in employment between 1999 and 2008,

\footnotetext{
${ }^{8}$ Note that $E P L_{k}$ and fire $_{j}$ do not appear separately because they are absorbed by fixed effects.
} 
and a state's exposure to sunset industries is the average growth of the sectors they produce, weighted by the labor force in 1999 .

Table 4 presents the same regression as those in column 1 of Table 1, but the sample is split into states whose production is mostly in slow-growing sectors (column 1), mostly in fast-growing sectors (column 2), and all sectors (column 3). The coefficients on the variable of interest, Age x EPL, is approximately double for the states focusing on fast-growing sectors, which is the opposite direction from what one would expect if the states heavy in sunset industries are more likely to protect older workers. Table 5 presents analogous results for the regression in column 1 of Table 2. Here the coefficient on Age $\mathrm{x}$ EPL $x$ Firing is essentially the same in the states focusing on faster-growth industries, which provides some confidence that the results are not being driven by a state's composition of slow- and fast-growing industries.

\subsubsection{Plant-level results: Prediction 3}

Next, consider problems of selection when estimating Equation (11) for plants above and below 100 workers. The concern is that plants' decision to cross the 100-worker threshold is itself impacted by EPL. One way to address the selection issue is to consider plants that are further from the threshold, because a plant far above or far below 100 workers would likely be on the same side of 100 even if EPL were weaker or stronger. I estimate this regression again in Table 6 using thresholds of 75 and 125 workers, and find similar results, with an F-test rejecting equality of coefficients on the interaction term for the US at the 1 percent level (column 1 compared to column 2) and for Latin American countries at the 5 percent level (column 3 compared to column 4) respectively.

I also present a number of sensitivity checks in Online Appendix B.

\section{Conclusion}

I have presented a theoretical model and empirical evidence that EPL shifts formal sector jobs away from young workers in favor of older workers. This happens because a plant would rather not commit itself to a young worker for future periods, which distorts the hiring decision. Then when the plant does decide to hire a young worker, it will retain her when she is old, even if it would prefer to fire her, and both of these effects raise the age composition of the plant.

The empirical test of this prediction follows the methodology pioneered by Rajan and Zingales (1998). I assume that those manufacturing sectors with a high involuntary separation rate in the United States (or Latin America) would also have a high firing rate in India in the absence of EPL, and that 
those manufacturing sectors are most heavily impacted by EPL. Older workers are especially likely to find formal sector jobs in high-separation sectors in strict-EPL states, which is exactly what we would expect if EPL shifts jobs from younger workers to older workers.

In the second part of the paper, I follow a similar strategy, and assume that plants in high-separation manufacturing sectors are especially impacted by EPL. I find that the interaction of firing rate and EPL is an important predictor of TFP, but only among plants large enough to be under the purview of EPL, and conclude that EPL reduces TFP.

It is believable that the shift in jobs from young to old workers is causing the reduction in TFP, and this is the channel that is emphasized in the theory section, but it is possible that some other mechanism is responsible for the reduction in TFP. Separating out the relative importance of the different mechanisms will be a topic for future research.

\section{Acknowledgements}

I would like to thank Treb Allen, Amrit Amirapu, Sam Bazzi, Anne Derbes, Eric Werker, Michael Gechter, Lakshmi Iyer, William Johnson, Kavan Kucko, Kevin Lang, Dilip Mookherjee, Peter Murell, Daniele Paserman, Amanda Schmidt, Robert Schwab, Amanda Schmidt, Ben Solow, Vidhya Soundarajan as well as seminar participants at Boston University and the Advanced Graduate Workshop on Poverty, Development, and Globalization. I would also like to thank An Yang and Raisa Behal for excellent research assistance.

\section{Data availability}

The Stata .do files used to create the tables and the underlying data are freely available in Mendeley at http://doi.org/10.17632/rzfwmgyf5c.1.

\section{References}

Ahsan, Ahmad and Carmen Pagés, "Are all labor regulations equal? Evidence from Indian manufacturing," Journal of Comparative Economics, 2009, 37 (1), 62-75.

Amirapu, Amrit and Michael Gechter, "Labor regulations and the cost of corruption: Evidence from the Indian firm size distribution." IED Working Paper, 266.

Autor, David, H, William R Kerr, and Adriana D Kugler, "Does employment protection reduce 
productivity? Evidence from US states," The Economic Journal, 2007, 117 (521), 189-217.

Bassanini, Andrea, Luca Nunziata, and Danielle Venn, "Job protection legislation and productivity growth in OECD countries," Economic Policy, 2009, 24 (58), 349-402.

Bertrand, Marianne, Esther Duflo, and Sendhil Mullainathan, "How much should we trust differences-in-differences estimates?" The Quarterly Journal of Economics, 2004, 119 (1), 249275.

Besley, Timothy and Robin Burgess, "Can labor regulation hinder employment performance? Evidence from India," Quarterly Journal of Economics, 2004, 17 (3), 91-134.

Bhattacharjea, Aditya, "How do Indian firms respond to employment protection legislation?" University of Delhi. Mimeo, 2008.

Bollard, Albert, Peter J Klenow, and Gunjan Sharma, "India's mysterious manufacturing miracle," Review of Economic Dynamics, 2013, 16 (1), 59-85.

Chaurey, Ritam, "Labor regulations and contract labor use: Evidence from Indian firms," Journal of Development Economics, 2015, 114, 224-232.

Davis, Steven J and John Haltiwanger, "Gross job flows," Handbook of labor economics, 1999, 3, 2711-2805.

Donald, Stephen G, and Kevin Lang, "Inference with difference-in-differences and other panel data", The Review of Economics and Statistics, 2007, 89 (2), 221-233.

Dougherty, Sean M, Veronica C Frisancho Robles, and Kala Krishna, "State-level labor reform and firm-level productivity in India," India Policy Forum, 2014, 10.

Esping-Andersen, Gøsta, Why we need a new welfare state, Oxford University Press, 2002.

Economic for Center and Policy Research, "CPS displaced worker uniform extracts," various years.

Government of India, "Annual Survey of Industries", Central Statistical Office, Ministry of Statistics and Programme Implementation, Government of India, Kolkata. Various years.

Gupta, Poonam, Rana Hasan, and Utsav Kumar, "Big reforms but small payoffs: Explaining the weak record of growth in Indian manufacturing," 2009. In S. Bery, B. Bosworth, and A. Panagariya (eds.), India Policy Forum, Vol. 5. Washington, DC: Brookings Institution.

Harrison, Ann E, Leslie A Martin, and Shanthi Nataraj, "Learning versus stealing: how important are market-share reallocations to India's productivity growth?" The World Bank Economic Review, 2013, 27 (2), 202-228.

Hasan, Rana, and Karl Jandoc, "Labor regulations and firm size distribution in Indian manufacturing." and economic transformation in India, 2013, 15-48.

Heckman, James and Carmen Pagés, "The cost of job security regulation: Evidence from Latin Amer- 
ican labor markets," Economica, 2000, 1 (1), 109-54.

Kumar, H L, Practical guide to contract labor regulation \& abolition act \& rules, Universal Law Publishing, 2008.

Levinsohn, James and Amil Petrin, "Estimating production functions using inputs to control for unobservables," The Review of Economic Studies, 2003, texitit70 (2), 317-341.

Malik, P, "Industrial law: A manual of central labor and industrial laws incorporating state amendments with rules," Regulations and Select Notifications, Lucknow: Eastern Book Company, 2011.

Micco, Alejandro and Carmen Pagés, "The economic effects of employment protection: evidence from international industry-level data," 2006. Inter-American Development Bank, Washington DC.

Montenegro, Claudio E and Carmen Pagés, "Who benefits from labor market regulations? Chile, 1960-1998" in J. Heckman and C. Pagés (eds.) Law and Employment: Lessons from Latin America and the Caribbean. Chicago: University of Chicago Press, 401-434. 2004.

OECD, "Employment protection regulation and labor market performance," Employment Outlook 2004, $61-125$.

OECD, "OECD economic surveys: India," OECD Publications, 2007.

Okudaira, Hiroko, Miho Takizawa, and Kotaro Tsuru, "Employment protection and productivity: Evidence from firm-level panel data in Japan," Applied Economics, 2013, 45 (15), 2091-2105.

Pissarides, Christopher A, "Employment protection," Labor economics, 2001, 8 (2), 131-159.

Rajan, Raghuram G, and Luigi Zingales. "Financial Dependence and Growth." The American Economic Review, 1998, 88 (3), 559-586.

Rajeev, Meenakshi. "Contract labor act in India: A pragmatic view." International Journal of Economic Policy in Emerging Economies, 2010, 3(3), 237-252.

Skedinger, Per, "Employment policies and displacement in the youth labor market," Swedish Economic Policy Review, 1995, 2, 135-171.

World Bank, "Doing business 2009: Comparing regulations in 181 economies," World Bank Publications, 2008.

World Bank, "Doing business: Measuring business regulations," World Bank Publications, 2015. 


\section{Tables}

Table 1. Formality, age, and employment protection legislation

\begin{tabular}{lcc}
\hline & $(1)$ & $(2)$ \\
\hline Age x EPL & $\begin{array}{c}0.907 * * \\
(0.342)\end{array}$ & $\begin{array}{c}4.262 * * \\
(1.689)\end{array}$ \\
Age & -0.002 & $-0.010 * *$ \\
& $(0.001)$ & $(0.005)$ \\
Male & $0.057 * * *$ & $0.279 * * *$ \\
& $(0.018)$ & $(0.108)$ \\
\hline Observations & 22898 & 22898 \\
Model & Linear & Probit \\
Individual controls & Yes & Yes \\
R-squared & 0.338 & 0.321 \\
\hline
\end{tabular}

The dependent variable is 1 if the worker is formal and 0 otherwise. State-sector, state-year, and sector-year fixed effects, and an indicator variable for level of education and rural/urban, are not reported. EPL is absorbed by fixed effects. Probit coefficients are marginal effects at the mean. Standard errors (in parentheses) are clustered at the state level.

Note: $* \mathrm{p}<.1 * * \mathrm{p}<.05 * * * \mathrm{p}<.01$. 
Table 2. Formality, age, separation rate, and EPL

\begin{tabular}{|c|c|c|c|c|}
\hline & (1) & (2) & (3) & (4) \\
\hline Age $x$ EPL $x$ Firing (US) & $\begin{array}{c}0.084 * * \\
(0.029)\end{array}$ & $\begin{array}{c}0.386 * * * \\
(0.095)\end{array}$ & & \\
\hline Age $x$ EPL x Firing (Latin Am.) & & & $\begin{array}{c}0.139 * * \\
(0.065)\end{array}$ & $\begin{array}{c}0.935^{* * * *} \\
(0.139)\end{array}$ \\
\hline Age & $\begin{array}{l}-0.001 \\
(0.002)\end{array}$ & $\begin{array}{l}-0.004 \\
(0.007)\end{array}$ & $\begin{array}{c}0.001 \\
(0.001)\end{array}$ & $\begin{array}{c}0.012 * * \\
(0.005)\end{array}$ \\
\hline Male & $\begin{array}{c}0.057 * * * \\
(0.018)\end{array}$ & $\begin{array}{c}0.279 * * * \\
(0.105)\end{array}$ & $\begin{array}{c}0.059 * * * \\
(0.017)\end{array}$ & $\begin{array}{c}0.298 * * * \\
(0.102)\end{array}$ \\
\hline Observations & 22898 & 22898 & 20756 & 20756 \\
\hline Model & Linear & Probit & Linear & Probit \\
\hline Individual controls & Yes & Yes & Yes & Yes \\
\hline R-squared & 0.338 & 0.321 & 0.289 & 0.289 \\
\hline
\end{tabular}

The dependent variable is 1 if the worker is formal and 0 otherwise. State-sector, stateyear, and sector-year fixed effects, and an indicator variable for level of education and rural/urban, are not reported. EPL, firing rate, and their interaction are absorbed by fixed effects. Age x EPL and Age x Firing are included in the regression but not displayed. Probit coefficients are marginal effects at the mean. Standard errors (in parentheses) are clustered at the state level.

Note: $* \mathrm{p}<.1 * * \mathrm{p}<.05 * * * \mathrm{p}<.01$. 
Table 3. The relationship between TFP, EPL, and separation rates in large and small plants

\begin{tabular}{lcccc}
\hline & $(1)$ & $(2)$ & $(3)$ & $(4)$ \\
\hline EPL x Firing (US) & $\begin{array}{c}-4.210^{* * *} \\
(1.10)\end{array}$ & $\begin{array}{c}-0.704 \\
(1.75)\end{array}$ & & \\
EPL x Firing (Latin Am.) & & & $-12.478 * *$ & -2.986 \\
& & & $(4.82)$ & $(3.15)$ \\
Log labor & $0.216 * * *$ & $0.224 * * *$ & $0.266 * * *$ \\
& $(0.02)$ & $(0.02)$ & $(0.02)$ & $0.284 * * *$ \\
& 54080 & 126785 & 43906 & 99734 \\
\hline Observations & $100+$ & $1-99$ & $100+$ & $1-99$ \\
Plant size & 0.756 & 0.632 & 0.694 & 0.640 \\
R-squared & & & & \\
\hline
\end{tabular}

The dependent variable is plant-level log TFP. The sample is divided between plants with below 100 (no EPL) and above 100 (with EPL) workers. Stateyear and sector-year fixed effects are not reported. EPL and firing rate are absorbed by fixed effects. Standard errors (in parentheses) are clustered at the state level.

Note: $* \mathrm{p}<.1 * * \mathrm{p}<.05 * * * \mathrm{p}<.01$. 
Table 4. Formality, age, and employment protection legislation: States producing high- and low-growth goods

\begin{tabular}{lccc}
\hline & $(1)$ & $(2)$ & $(3)$ \\
\hline \multirow{2}{*}{ Age x EPL } & $0.624^{* * *}$ & $1.256^{* *}$ & $0.907^{* *}$ \\
& $(0.178)$ & $(0.465)$ & $(0.342)$ \\
Age & -0.002 & -0.002 & -0.002 \\
& $(0.001)$ & $(0.002)$ & $(0.001)$ \\
Male & $0.080^{* *}$ & 0.036 & $0.057^{* * *}$ \\
& $(0.030)$ & $(0.019)$ & $(0.018)$ \\
\hline Observations & 10843 & 12055 & 22898 \\
Model & Linear & Linear & Linear \\
Growth of state & Slow & Fast & All \\
R-squared & 0.323 & 0.353 & 0.338 \\
\hline
\end{tabular}

The dependent variable is 1 if the worker is formal and 0 otherwise. Statesector, state-year, and sector-year fixed effects, and an indicator variable for level of education and rural/urban, are not reported. EPL is absorbed by fixed effects. States are split into fast- and slow-growth based on their production of fast- and slow-growing sectors. Standard errors (in parentheses) are clustered at the state level.

Note: $* \mathrm{p}<.1 * * \mathrm{p}<.05 * * * \mathrm{p}<.01$. 
Table 5. Formality, age, separation rate, and EPL: States producing high- and low-growth goods

\begin{tabular}{lccc}
\hline & $(1)$ & $(2)$ & $(3)$ \\
\hline Age x EPL x Firing (US) & $0.060^{*}$ & 0.062 & $0.084 * *$ \\
& $(0.027)$ & $(0.033)$ & $(0.029)$ \\
Age & -0.002 & -0.000 & -0.001 \\
& $(0.002)$ & $(0.002)$ & $(0.002)$ \\
Male & $0.078^{* *}$ & $0.038^{*}$ & $0.057 * * *$ \\
& $(0.030)$ & $(0.019)$ & $(0.018)$ \\
\hline Observations & 10843 & 12055 & 22898 \\
Model & Linear & Linear & Linear \\
Growth of state & Slow & Fast & All \\
R-squared & 0.324 & 0.354 & 0.338 \\
\hline
\end{tabular}

The dependent variable is 1 if the worker is formal and 0 otherwise. State-sector, stateyear, and sector-year fixed effects, and an indicator variable for level of education and rural/urban, are not reported. EPL, firing rate, and their interaction are absorbed by fixed effects. Age x EPL and Age x Firing are included in the regression but not displayed. States are split into fast- and slow-growth based on their production of fast- and slowgrowing sectors. Standard errors (in parentheses) are clustered at the state level.

Note: $* \mathrm{p}<.1 * * \mathrm{p}<.05 * * * \mathrm{p}<.01$. 
Table 6. The relationship between TFP, EPL, and separation rates in large and small plants: Different plant-size threshold

\begin{tabular}{lcccc}
\hline & $(1)$ & $(2)$ & $(3)$ & $(4)$ \\
\hline EPL x Firing (US) & $\begin{array}{c}-3.281 * * \\
(1.22)\end{array}$ & $\begin{array}{c}-0.585 \\
(1.76)\end{array}$ & & \\
EPL x Firing (Latin Am.) & & & $-12.952 * *$ & -2.621 \\
& & & $(5.41)$ & $(3.13)$ \\
Log labor & $0.223 * * *$ & $0.237 * * *$ & $0.269 * * *$ & $0.297 * * *$ \\
& $(0.02)$ & $(0.02)$ & $(0.02)$ & $(0.02)$ \\
\hline Observations & 46464 & 118959 & 37670 & 93465 \\
Plant size & $125+$ & $1-75$ & $125+$ & $1-75$ \\
R-squared & 0.760 & 0.629 & 0.688 & 0.638 \\
\hline
\end{tabular}

The dependent variable is plant-level log TFP. The sample is divided between plants with 75 and below (no EPL) and 125 and above (with EPL) workers. State-year and sector-year fixed effects are not reported. EPL and firing rate are absorbed by fixed effects. Standard errors (in parentheses) are clustered at the state level.

Note: $* \mathrm{p}<.1 * * \mathrm{p}<.05 * * * \mathrm{p}<.01$. 
Figure 1. Observed formality by age in states with stricter or laxer EPL.

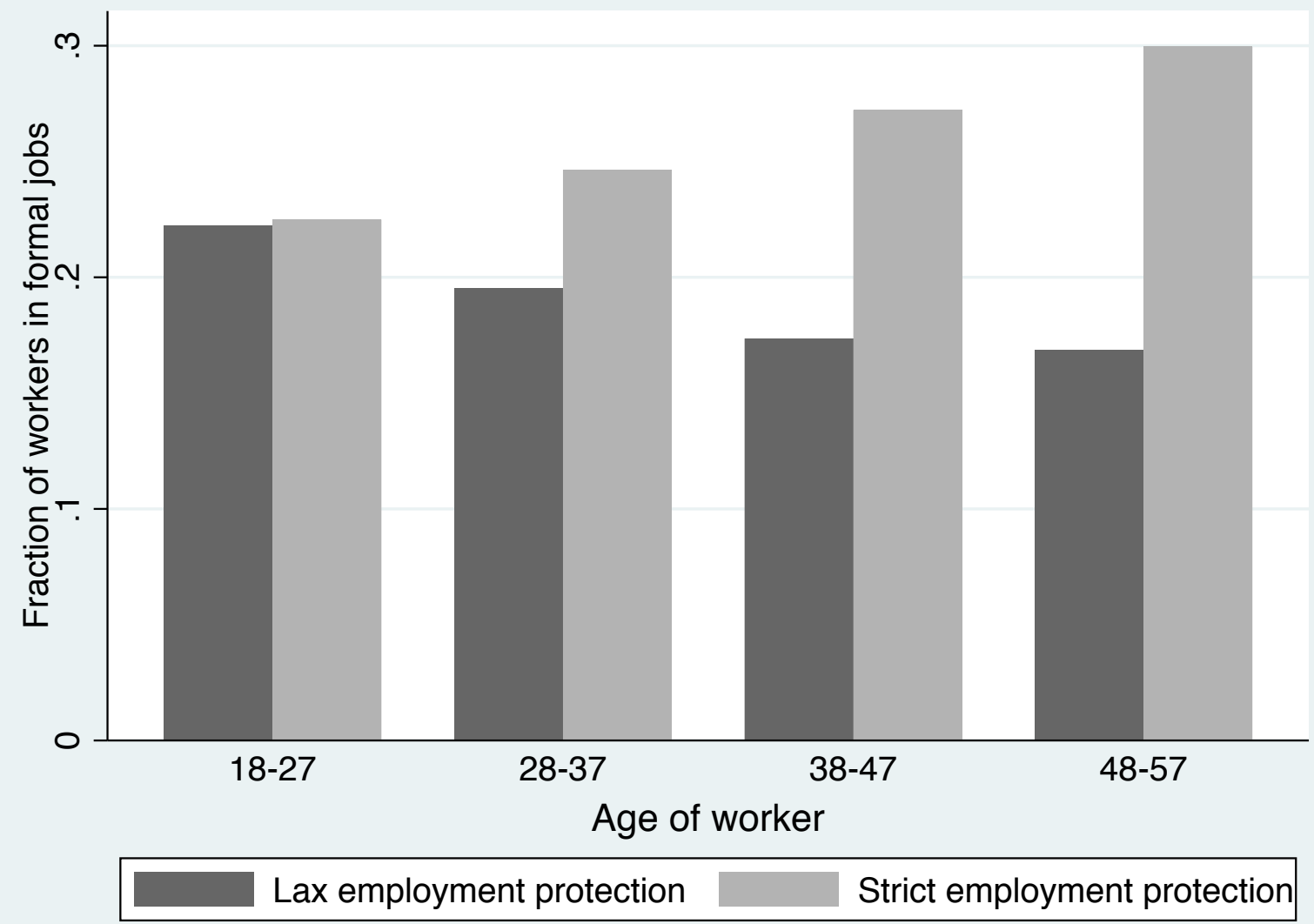

Percentage of workers who are formal in states with stricter or laxer EPL compared to the median.

\section{Online Appendix A: Theory}

In this appendix I provide details for several assertions made in the theory portion.

Claim 1: For all $(e, f, \beta) \in(0,1) \times(-1 / 2,1 / 2) \times(0,1)$,

$$
\frac{\partial}{\partial e} \frac{z^{*}}{1+e z^{*}}<0
$$

Proof: We know that for $e>0$,

$$
z^{*}=\frac{\sqrt{\beta e+2 \beta e f+1}-1}{\beta e},
$$




$$
\begin{aligned}
\frac{\partial}{\partial e} \frac{z^{*}}{1+e z^{*}}= & {\left[\beta^{2}(-(2 e f+e))+-4 \sqrt{\beta(2 e f+e)+1}+4+\right.} \\
& 2 \beta(-e(2 f+1)(\sqrt{2 \beta e f+\beta e+1}-2)+\sqrt{2 \beta e f+\beta e+1}-1)] / \\
& 2 e^{2} \sqrt{\beta(2 e f+e)+1}(\sqrt{\beta(2 e f+e)+1}+\beta-1)^{2}
\end{aligned}
$$

While not visually obvious, it can be verified that the expression above is negative for all valid values of $e, f$, and $\beta$, so $\frac{\partial}{\partial e} \frac{z^{*}}{1+e z^{*}}<0$

Claim 2: For all $(e, f, \beta) \in(0,1) \times(-1 / 2,1 / 2) \times(0,1)$,

$$
\frac{\partial}{\partial e \partial f} \frac{z^{*}}{1+e z^{*}}<0
$$

Proof:

$$
\frac{\partial}{\partial e \partial f} \frac{z^{*}}{1+e z^{*}}=-\frac{\beta^{3}(2 f+1)(3 \sqrt{\beta(2 e f+e)+1}+\beta-1)}{2(\beta(2 e f+e)+1)^{3 / 2}(\sqrt{\beta(2 e f+e)+1}+\beta-1)^{3}}
$$

The denominator is positive, and the numerator is positive as well, because $2 f+1>0$. There is a negative sign applied to the whole fraction, so the right-hand side is negative.

Claim 3: For all $(e, f, b) \in(0,1) \times(-1 / 2,1 / 2) \times(0,1)$,

$$
\frac{\partial}{\partial e} \phi(e, f, \beta)<0
$$


Proof: We know from above that $V(z)=\left(-1+2 f-z-2 f z+z^{2}-e z \beta+2 e f z \beta\right) /(2(-1+$ $\beta)(1+e z \beta))+\underline{\theta} /(1+\beta)$, and the firm chooses the optimal value for $z$, so we can replace $z$ with $z^{*}$, and differentiate with respect to $e$.

$$
\frac{\partial}{\partial e} \phi(e, f, \beta)=-\frac{(2 b e f+\beta e)(\sqrt{2 \beta e f+\beta e+1}-3)+4(\sqrt{2 \beta e f+\beta e+1}-1)}{2(1-\beta) \beta^{2} e^{3} \sqrt{\beta(2 e f+e)+1}}
$$

Differentiation with respect to $f$ gives

$$
\frac{\partial}{\partial e \partial f} \phi(e, f, \beta)=\frac{1}{2(1-\beta) \beta^{2} e^{3}}\left[-2 \beta e+\frac{\beta e(3 \beta(2 e f+e)+2)}{\beta(2 \beta e f+e+1)^{3 / 2}}\right]
$$

It can be verified that this expression is negative over the allowed values $e, f$, and $\beta$.

\section{Online Appendix B: Empirics}

\section{Data}

In Online Appendix Table B1, I present the ratings of EPL strength by state. They are based on Besley and Burgess (2004), Bhattacharjea (2008), and OECD (2007). These papers use different scales, and they have all been converted to a weak $(-1)$, neutral $(0)$, or strong $(+1)$ EPL category by Gupta et al. (2009). The last column indicates the sum of the three ratings for each state, and is what I use for an overall EPL rating. 
Online Appendix Table B1: EPL ratings by state

\section{BB Bhat. OECD Aggregate}

State

$\begin{array}{rrrrr}\text { Andhra Pradesh } & -1 & 0 & -1 & -2 \\ \text { Assam } & 0 & 0 & 1 & 1 \\ \text { Bihar } & 0 & 0 & 1 & 1 \\ \text { Gujurat } & 0 & 0 & -1 & -1 \\ \text { Haryana } & 0 & 0 & -1 & -1 \\ \text { Karnataka } & -1 & -1 & 0 & -2 \\ \text { Kerala } & -1 & 0 & 1 & 0 \\ \text { Madhya Pradesh } & 0 & 0 & 0 & 0 \\ \text { Maharashtra } & 1 & 1 & 1 & 3 \\ \text { Orissa } & 1 & 1 & 0 & 1 \\ \text { Punjab } & 0 & 0 & 0 & 0 \\ \text { Rajasthan } & -1 & 0 & -1 & -2 \\ \text { Tamil Nadu } & -1 & -1 & 0 & -2 \\ \text { Uttar Pradesh } & 0 & -1 & -1 & -2 \\ \text { West Bengal } & 1 & 0 & 1 & 2\end{array}$

Online Appendix Table B2 presents the (inverse) rank of involuntary job loss rates in the United States and a group of Latin American countries. A low number indicates a low level of job loss. See the body of the paper for more information.

\section{Sensitivity analysis}

In this section I consider variations of the regressions presented to test for sensitivity. Results are available on request.

I modify the regressions that produce Tables 1 and 2 in a variety of ways. First, instead of using the aggregate EPL rating, I use each of the three component ratings (Besley Burgess 2004, Bhattacharjea 2008, and OECD 2007) separately. The results are similar. All coefficients remain the same sign, and while several results lose significance, some become stronger.

In a second set of tests, I treat the aggregate EPL score as a categorical variable rather than a continuous variable. The coefficients follow the broad pattern that would be expected, where the coefficients on the higher levels of EPL are generally larger. The coefficients do not move linearly though, possibly because there are few states in some of the EPL categories. 
Online Appendix Table B2: Rank of involuntary job loss rates by sector

NIC-2004

code
IJLR

US Latin Am.

Manufacturing sector

Food manufacturing

Textiles

Clothing

Luggage and shoes

Wood products

Paper products

Publishing

Coke, refined petroleum

Chemical products

Rubber and plastics

Non-metallic mineral products

Basic metals

Fabricated metals

Machinery n.e.c.

Office and computing machinery

Electrical machinery

TV and communication

Medical, optical, clocks

Motor vehicles

Other transport equipment
15

17

18

19

20

21

22

23

24

25

26

27

28

29

30

31

32

33

34

35

9

11

11

11

13

6.5

$\begin{array}{ll}7.5 & 6.5\end{array}$

23

43

$13 \quad 3$

$5 \quad 5$

$14.5 \quad 1$

$14.5 \quad 8$

3 -

16

9

12

20

10.5

10.5

Next, I estimate each of the regressions in Tables 1 and 2 dropping each state one at a time, and doing the same for sectors. The results stay very similar throughout. I also drop the self-employed, use a wide variety of different fixed effects specifications, and include different individual controls. The results in all cases remain substantively the same. 